Research Article

\title{
Frost-Resistant Epoxy-Urethane Binders Containing Diglycidyl Urethane
}

\author{
Vladimir N. Strel'nikov, Valeriy Yu. Senichev (D, Alexey I. Slobodinyuk, Anna V. Savchuk, \\ and Elena R. Volkova
}

Institute of Technical Chemistry, Perm's Federal Research Centre of Ural Branch of Russian Academy of Sciences, Perm 614013, Russia

Correspondence should be addressed to Valeriy Yu. Senichev; senichev85@yandex.ru

Received 31 August 2018; Accepted 12 February 2019; Published 21 April 2019

Academic Editor: Ulrich Maschke

Copyright ( 2019 Vladimir N. Strel'nikov et al. This is an open access article distributed under the Creative Commons Attribution License, which permits unrestricted use, distribution, and reproduction in any medium, provided the original work is properly cited.

\begin{abstract}
A novel method for developing frost-resistant epoxy-urethane binders is proposed that is based on mixtures of epoxy-urethane oligomers and diglycidyl urethane formed during synthesis. The microheterogeneous elastic materials obtained by curing these mixtures by the cycloaliphatic amines have a low glass transition temperature and high mechanical properties.
\end{abstract}

\section{Introduction}

Elastic compositions based on epoxy-urethane oligomers (EUOs) are used as adhesives [1-5], are the basis of compounds for various purposes, are resistant to humidity and corrosive environments [6-10], and are also components for biodegradable materials [11]. They have a wide variety of applications because of their excellent adhesion to different materials and good dielectric and mechanical properties. They are characterized by the presence of urethane groups in the chain and end epoxy groups.

The EUOs are synthesized from oligodiols, diisocyanates, and epoxy alcohols. As a rule, the synthesis is carried out in two stages. In the first stage, a reaction is carried out between the oligodiol and diisocyanate to form the oligodiisocyanate. In the second stage, a reaction occurs between the obtained oligodiisocyanate and the epoxy alcohol [12-15]. Amines, dicarboxylic acid anhydrides, and compounds with carboxyl groups are used as hardeners for the obtained EUOs [16]. Curing of this type of material is provided, as a rule, at a temperature of $70^{\circ} \mathrm{C}-90^{\circ} \mathrm{C}$.

The use of polymer materials in the Arctic requires a decrease in the temperature limit for their operation down to $-70^{\circ} \mathrm{C}$. Similar materials with satisfactory frost resistance were developed on the basis of oligodieneurethane epoxides, in which the glass transition temperature reaches $-76^{\circ} \mathrm{C}$ [16]. However, a significant drawback of such materials is low strength, as it may not be higher than $5 \mathrm{MPa}$. It is known that the strength properties of EUO-based compositions can be increased by introducing a certain amount of epoxy resin [17]. However, this modification is usually accompanied by the appearance of problems associated with ensuring the necessary deformability of the material, which is especially important at low temperatures.

In authors' opinion, the solution to the problem of developing a frost-resistant elastic material with high mechanical characteristics lies in the field of the use of polyetherurethane epoxides. Their glass transition temperature can be lowered below $-70^{\circ} \mathrm{C}$, but they have a much higher level of interchain interaction that can lead to better strength properties compared to polydieneurethane epoxides [18].

In this paper, the results of studies for the dramatic improvement of the strength properties of compositions based on EUOs on the directed regulation of the structure of the resulting frost-resistant material are presented.

\section{Materials and Methods}

2.1. Materials. The studies were carried out using a series of urethane-epoxide oligomers synthesized on the base of 


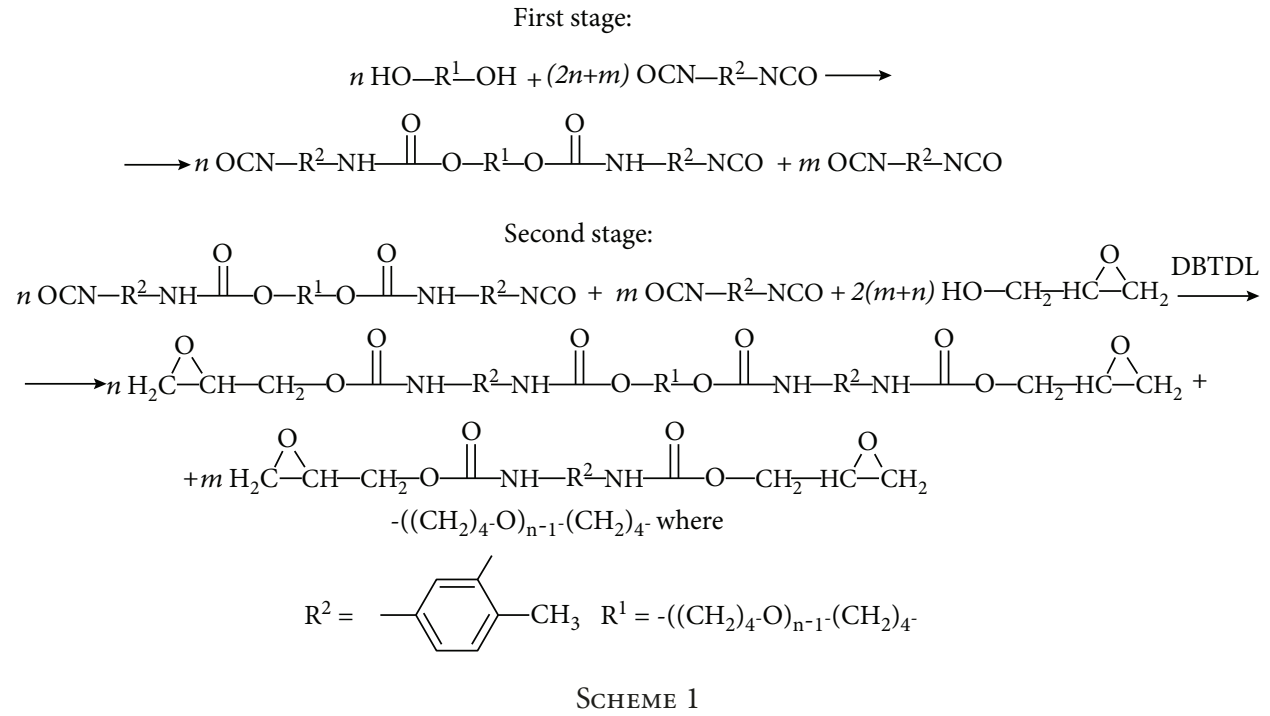

urethane-containing pseudo-prepolymers with terminal functional isocyanate groups (oligotetramethylene oxide urethane diisocyanates) and glycidol. The synthesis of the mentioned pseudopolymers was carried out on the base of polytetramethyleneoxide diol oligoether with a molecular mass 1400 (PTMO-1400) and 2,4-toluene diisocyanate (TDI). The molar ratio between the $\mathrm{NCO}$ groups and $\mathrm{OH}$ groups in the synthesis was provided from 2.03 to 4.03 . The true prepolymer is obtained if this ratio is equal to 2 for the reaction between diols and diisocyanates. The final reaction product is a pseudo-prepolymer at the higher values of the mentioned ratio; in this case, it is a mixture of the true prepolymer and the initial diisocyanate.

Previously, PTMO- 1400 was dried at $80^{\circ} \mathrm{C}$ with stirring and a residual pressure of $1-2 \mathrm{kPa}$. The first stage of the synthesis was carried out in a hermetic laboratory mixer with a jacket for heating. After loading the components, the temperature was maintained at $60^{\circ} \mathrm{C}$ for 1 hour, then it was raised to $80^{\circ} \mathrm{C}$ and maintained with stirring for 6 hours. Achieving a constant content of isocyanate groups was carried out by reverse titration with n-butylamine in accordance with ASTM D2572-080.

In the second stage, the obtained pseudo-prepolymers were treated with glycidol at a molar ratio of $\mathrm{OH}: \mathrm{NCO}=2$ $: 1$. This synthesis step was carried out at $70^{\circ} \mathrm{C}$ in the aforementioned mixer. The completeness of the NCO group conversion was monitored by Fourier-transform infrared (FTIR) spectroscopy after the disappearance of the absorption band at $2270 \mathrm{~cm}^{-1}$. Synthesis of the EUO was almost finished in 5 hours. The content of the free epoxy groups was determined according to [19].

The ratio between final oligomers depends on the ratio between the $n$ and $m$ parameters (Scheme 1); $n$ is the number of the oligodiol moles; $m$ is the number of diisocyanate moles taken in excess.

Synthesized oligomers were used to prepare cured samples for the study of their physicomechanical and other functional properties. Two liquid cycloaliphatic amines were used as the hardener: 3-aminomethyl-3,5,5-trimethylcyclohexylamine (IFDA) and aminoethylpiperazine (AEP), which simultaneously contain primary, secondary, and tertiary nitrogen atoms. The molar ratio of EUO to amine was 1 to 0.87 using $\mathrm{AEP}$, and it was 1 to 0.75 when using IFDA. These ratios were chosen earlier according to experimental values of the tensile strength of similar materials given elsewhere [20].

During the curing reaction, the EUO was stirred with an amine for 5 minutes under vacuum $(1-2 \mathrm{kPa})$ at $25^{\circ} \mathrm{C} \pm 1^{\circ} \mathrm{C}$. The resulting reaction mixture was cured for 24 hours at $25^{\circ} \mathrm{C} \pm 1^{\circ} \mathrm{C}$ in slotted metal forms. The mentioned curing time was determined preliminary using FTIR spectroscopy method. The absorption band at $910 \mathrm{~cm}^{-1}$ referring to the free epoxy groups for all investigated compositions based on EUOs and amines disappears at the mentioned temperature within 20-24 hours [21-23].

2.2. Methods. The softening point of the hard phase, $T_{S}$, was determined by thermomechanical analysis on a TMA/SDTA 841e METTLER TOLEDO device at a scanning rate of $0.05 \mathrm{deg} \cdot \mathrm{s}^{-1}$ under a load of $0.015 \mathrm{MPa}$. The glass transition temperature, $T_{g}$, was determined by differential scanning calorimetry (DSC) on the DSC 822e METTLER TOLEDO calorimeter at a scanning rate of $0.08 \mathrm{deg} \cdot \mathrm{s}^{-1}$.

Mechanical tests of the obtained samples were carried out using a universal INSTRON 3365 test machine at a temperature of $25^{\circ} \mathrm{C} \pm 1^{\circ} \mathrm{C}$ and $-70^{\circ} \mathrm{C} \pm 1^{\circ} \mathrm{C}$ according to ISO $37-$ 2013. The engineer strength $\sigma_{\mathrm{k}}$ (the maximum stress calculated for the initial cross section of the sample), the relative critical deformation $\varepsilon_{\mathrm{k}}$, and the engineer modulus $E_{100}$ (the stress at the relative strain of a sample at $\varepsilon=100 \%$ ) were determined.

Bonding properties of the adhesive elastomer-metal joints were determined for 1017 carbon steel and 1050 aluminium alloy. The pull-off bonding strength, $\sigma_{\mathrm{po}}$, for the adhesive elastomer-steel joints was determined according to the Russian standard GOST 14760-69 using cylindrical samples with a polymer layer of $2 \pm 0.1 \mathrm{~mm}$ thickness between 
TABle 1: Properties of the synthesized oligomers.

\begin{tabular}{lccccc}
\hline EUO & \multirow{2}{*}{$\begin{array}{c}\text { NCO: OH molar ratio at the } \\
\text { pseudo-prepolymer synthesis }\end{array}$} & \multicolumn{3}{c}{$\begin{array}{c}\text { Content of free functional groups in oligomer (\%) } \\
\text { Isocyanate } \\
\text { (in pseudo-prepolymers) }\end{array}$} & \multicolumn{2}{c}{$\begin{array}{c}\text { Epoxy (in EUO) } \\
\text { Experimental }\end{array}$} & Calculated & Experimental \\
\hline EUO-1 & 2.03 & 4.79 & 4.75 & 4.52 & 4.23 \\
EUO-2 & 2.43 & 6.56 & 6.49 & 5.71 & 5.27 \\
EUO-3 & 2.73 & 7.72 & 7.62 & 6.56 & 6.39 \\
EUO-4 & 3.03 & 8.81 & 8.92 & 7.87 & 8.03 \\
EUO-5 & 4.03 & 12.07 & 12.22 & 10.28 & 10.41 \\
\hline
\end{tabular}

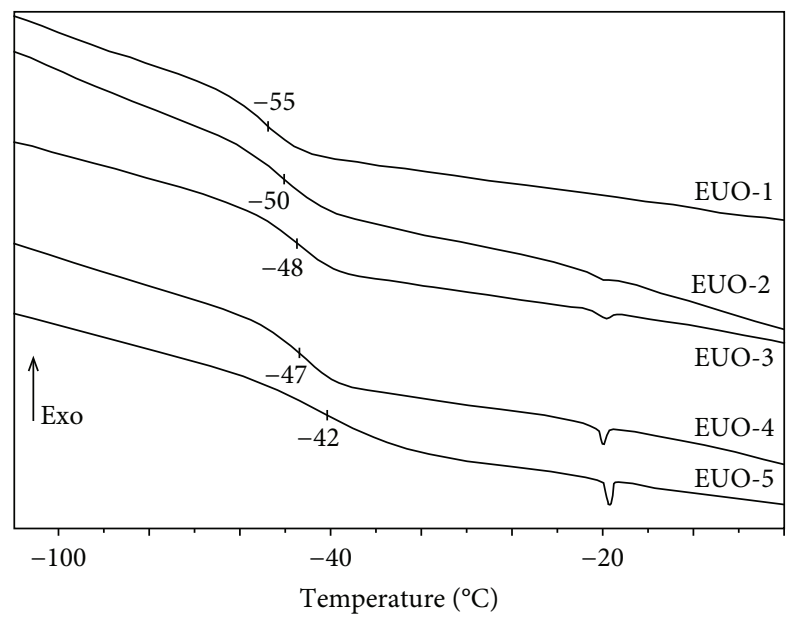

Figure 1: DSC thermograms of EUOs.

the metal cylinders (the test conditions are close to the ASTM C633 method). The shear bonding strength, $\sigma_{\text {sh }}$, of adhesive joints with aluminium was determined according to ASTM D3163.

The change in viscosity during the curing process of the epoxy-urethane compositions was studied using a rotational viscometer Rheotest 2.1 (Germany) with a cone-plate working assembly at a temperature of $25^{\circ} \mathrm{C} \pm 1^{\circ} \mathrm{C}$ and the shear rate of $180 \mathrm{~s}^{-1}$ [24]. The kinetic curves, $\eta(t)$, that characterize the change in the dynamic viscosity of the reaction mass over time were drawn on the basis of the rheological tests results.

\section{Results and Discussion}

Properties of the synthesized isocyanate-containing pseudoprepolymers and epoxidized oligomers based on them are shown in Table 1. Theoretical values for the content of the functional groups were calculated based on the molar ratios used between the monomers and their molecular weights.

A feature of the second stage of EUO synthesis is the formation of mixtures of oligomeric epoxy-urethane and diglycidyl urethane (DGU) when pseudo-prepolymers are used. The formation of such mixtures of monomers with oligomeric products, which differ significantly in structure, can lead to microphase separation during the curing stage. This is accompanied by the appearance of two glass transition temperatures in the final polymers. This effect is typical, for example, for segmented polyurethanes [25].

In the opinion of the authors, such a microphase separation can be a favourable factor for the formation of the optimal structure of frost-resistant compounds based on EUOs. This is because the glass transition temperature of the polymer matrix depends on the concentration of the DGU fragments in the polymer chain in a much lesser degree. At the same time, it can be hoped that the appearance of these fragments that have a rather hard structure in the chain will favourably affect the strength properties of the cured materials.

The DSC thermograms of synthesized EUOs are presented in Figure 1. The analysis of these thermograms shows that the glass transition temperature of the soft matrix naturally increases with an increase in the DGU fraction in the mixture, which is associated with a decrease in the mobility of the soft chains due to the formation of additional hydrogen bonds. At the same time, all curves show a melting peak at $20^{\circ} \mathrm{C}$, corresponding to the phase transition of the hard blocks containing DGU fragments. The intensity of this transition naturally increases with increasing diglycidyl urethane content.

Analysis of FTIR spectra in the area of carbonyl valence vibrations (wave number interval $v=1600-1760 \mathrm{~cm}^{-1}$ ) revealed important features of structural organization of studied objects (Figure 2). The results of spectral studies of some similar polymers with urethane groups were used to classify the corresponding absorption bands [26, 27].

The change in the intensity of the absorption bands of the polyepoxy-urethane (PUE) samples cured using IFDA and AEP hardeners is shown in Figure 3 for the range of 1600$1760 \mathrm{~cm}^{-1}$. Two absorption bands appear in spectra of PUE1 and PUE- 6 synthesized without excess of DGU. The band at $1702 \mathrm{~cm}^{-1}$ refers to the carbonyl bonded by the hydrogen bond to the $\mathrm{NH}$ group of the urethane hydroxyl hard block. The peak at $1730 \mathrm{~cm}^{-1}$ is related to the absorption of free carbonyl of the urethane group [18]. It should be noted that the intensity of the peak at $1730 \mathrm{~cm}^{-1}$ of the PUE- 1 sample is higher than that of the sample of the PUE- 6 (based on IFDA), which indicates a higher level of interchain interaction in the polymers cured by AEP. The intensity of peaks at $1702 \mathrm{~cm}^{-1}$ and $1730 \mathrm{~cm}^{-1}$ naturally increases while the fraction of hard blocks based on diglycidyl urethane rises without regard to the hardener type. 


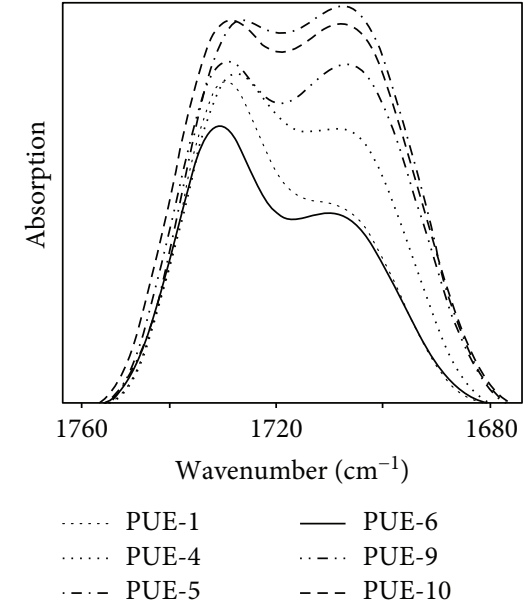

FIgURE 2: A fragment of FTIR spectra for PUE samples.

Two glass transition temperatures are clearly visible in the DSC thermograms for the cured PUE samples synthesized with an excess of DGU (Figure 3), which indicate a microheterogeneous structure of the investigated polymers. One can see the presence of one glass transition temperature of elastomers synthesized without an excess of DGU. It is interesting that the glass transition of a soft polymer matrix remained practically unchanged regardless of the DGU fraction. The formation of hard blocks in the polymer matrix due to the DGU hardening, corresponding to the appearance of the nanodispersed high-modulus filler, led to a significant increase in the engineer modulus, hardness, and strength of the cured material (Table 2). The appearance of the mentioned nanodispersed filler was described earlier for curing mixes of noncompatible oligomers [17, 28]. It should be noted that the glassing transition temperature of the soft phase in these materials is almost independent of the amount of the filler. The same effect is apparent in the discussed samples (Figure 3).

Figure 4 shows the kinetic curves for changes in the dynamic viscosity of reaction mixtures based on epoxyurethane oligomers using various hardeners. In all cases, the processes of chemical transformation began immediately after mixing the components and without an induction period. A correlation was observed between the gelation rate and the amount of DGU in the initial reaction mixture, despite the fact that the viscosity varied according to different laws, as indicated by the shape of the kinetic curves. The higher the amount of DGU in the initial oligomer, the higher the curing rate of the composition based on the EUO, which indicates the acceleration of chemical reactions accompanying the process of formation of spatial cross-linked structures [29]. In this case, not only a chemical but also a physical network was formed, which arose from the phase separation between the hard and soft blocks [30] and intermolecular interactions. These interactions were accompanied by a sharp increase in viscosity.

The maximum rate of the viscosity increase, which corresponds to the minimum viability time, is observed for systems based on EUO synthesized with a fourfold excess of TDI: namely, PUE-5 and PUE-10. The type of curing agent in this case had no significant effect on the gelling rate. But the initial viscosity, $\eta_{0}$, was almost 1.5 times higher for the PUE-10 composition compared to PUE-5. The influence of the hardener type was more pronounced for compositions based on EUO that were synthesized with a 2- and 3-fold excess of TDI. The viscosity of the compositions cured by the AEP changed according to a law close to the exponential one in the whole range (curves for PUE-1 and PUE-4). The exponential character of curves for the PUE compositions cured by IFDA is obvious for the initial part of the curing process (less than $10 \mathrm{~min}$ ). However, one can see a significant slowing of the gelling rate with a bend for curves corresponding to PUE-6 and PUE-9.

As shown by kinetic calculations, the experimental gelation time is more than an order of magnitude higher than the values calculated according to Flory [31], which is explained by the prevalence of chain elongation in the early stages of curing compared to cross-linking. A similar effect was previously observed by the authors for compositions based on oligodienepoxides and metaphenylenediamine.

It is known that the curing rate has a significant effect on the formation of a regular structure and on the physical and mechanical properties of urethane composites cured at low temperatures [32]. One can conclude the following upon comparing the results of rheological and physicomechanical (Table 2) studies. First, the higher the DGU content in a mixture with EUO, the shorter the viability of the composition on the basis of this EUO. Second, the use of an IFDA hardener produces materials with a higher viability and better physicomechanical properties.

The results of the mechanical tests given in Table 2 show that when the DGU content in the mixture with EUO increased, the engineer strength, the engineer modulus, and adhesion characteristics of the material significantly increased, while the relative critical strain naturally decreased.

It should be noted that the reinforcing effect was more clearly manifested with an increase in the fraction of DGU in materials cured by IFDA.

The hardening effect related with an increase in the content of DGU in mixes with EUOs is more pronounced for materials cured with IFDA. This effect, in our opinion, is associated with the formation of different structures of the hard phase in EUO when using different hardeners.

It was shown earlier that using isophorone diamine as a hardener of urethane-containing elastomers lead to the formation of a "loose" (poorly ordered) structure of the hard phase [33].

The formation of a "loose" hard phase is due to the bulky structure of IFDA. The loose structure of the hard phase promotes the dissipation of energy due to the crushing large hard blocks into smaller ones. This process leads the hardening effect of the material under tension. This effect was observed in the experiment for samples cured with IFDA (increase in the current modulus value in the last stages of strain-stress plots). It is interesting that similar effects were observed earlier for polyurethane ureas when using isophorone diisocyanate in the synthesis [34]. 


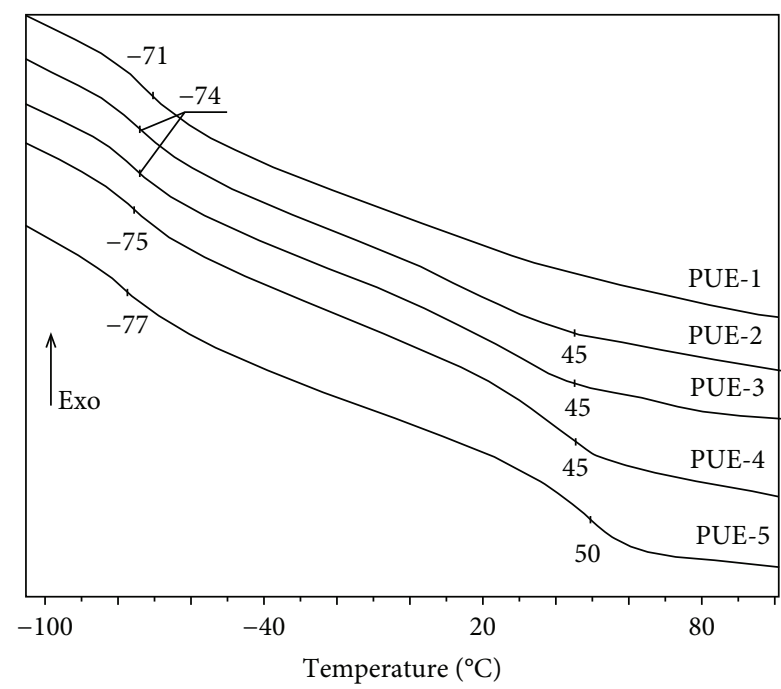

(a)

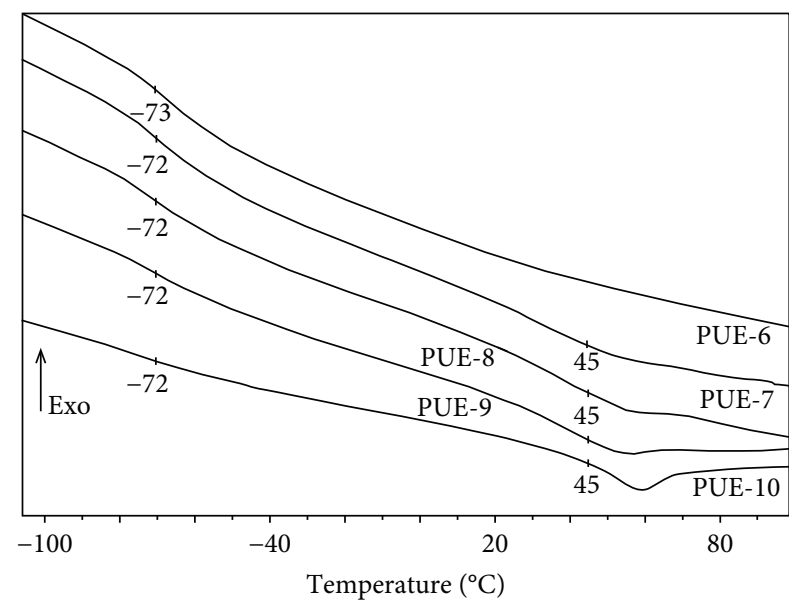

(b)

FIGURE 3: DSC thermograms of PUE samples.

TABle 2: Properties of cured PUE samples determined at two testing temperatures $T^{*}$.

\begin{tabular}{|c|c|c|c|c|c|c|c|c|c|c|c|}
\hline \multirow[t]{2}{*}{ Sample } & \multirow[t]{2}{*}{ EUO } & \multirow[t]{2}{*}{ Hardener } & \multirow[t]{2}{*}{$\begin{array}{l}\text { DGU volume fraction } \\
\text { in EUO-DGU mixtures }\end{array}$} & \multirow[t]{2}{*}{$T^{*}\left({ }^{\circ} \mathrm{C}\right)$} & \multirow[t]{2}{*}{$\sigma_{\mathrm{k}}(\mathrm{MPa})$} & \multirow[t]{2}{*}{$\varepsilon_{\mathrm{k}}(\%)$} & \multirow[t]{2}{*}{$E_{100}(\mathrm{MPa})$} & \multicolumn{2}{|c|}{$\begin{array}{c}\text { Bonding } \\
\text { strength } \\
(\mathrm{MPa})\end{array}$} & \multirow[t]{2}{*}{$T_{S}\left({ }^{\circ} \mathrm{C}\right)$} & \multirow[t]{2}{*}{$\begin{array}{l}\text { Shore A } \\
\text { hardness }\end{array}$} \\
\hline & & & & & & & & $\sigma_{\mathrm{po}}$ & $\sigma_{\mathrm{sh}}$ & & \\
\hline \multirow{2}{*}{ PUE-1 } & \multirow{2}{*}{ EUO-1 } & & \multirow{2}{*}{0.010} & 25 & 9.10 & 477 & 1.81 & 4.30 & 3.20 & \multirow{2}{*}{144} & \multirow{2}{*}{73} \\
\hline & & & & -70 & 49.00 & 7 & - & - & - & & \\
\hline \multirow{2}{*}{ PUE-2 } & \multirow{2}{*}{ EUO-2 } & & \multirow{2}{*}{0.085} & 25 & 13.10 & 340 & 5.30 & 6.90 & 4.30 & \multirow{2}{*}{146} & \multirow{2}{*}{88} \\
\hline & & & & -70 & 52.60 & 12 & - & - & - & & \\
\hline \multirow{2}{*}{ PUE-3 } & \multirow{2}{*}{ EUO-3 } & \multirow{6}{*}{ AEP } & \multirow{2}{*}{0.156} & 25 & 15.20 & 260 & 9.03 & 8.20 & 7.15 & \multirow{2}{*}{151} & \multirow{2}{*}{94} \\
\hline & & & & -70 & 56.30 & 8 & - & - & - & & \\
\hline \multirow{2}{*}{ PUE-4 } & \multirow{2}{*}{ EUO-4 } & & \multirow{2}{*}{0.217} & 25 & 16.20 & 221 & 11.20 & 8.30 & 7.20 & \multirow{2}{*}{155} & \multirow{2}{*}{96} \\
\hline & & & & -70 & 54.80 & 10 & - & - & - & & \\
\hline PUE-5 & EUO-5 & & 0.271 & 25 & 18.60 & 127 & 18.37 & 8.40 & 7.50 & 157 & 98 \\
\hline & & & & -70 & 53.80 & 19 & - & - & - & $15 /$ & 98 \\
\hline PUE-6 & EUO-1 & & 0.010 & 25 & 7.22 & 510 & 1.25 & 4.50 & 3.60 & 145 & 82 \\
\hline & & & & -70 & 45.38 & 7 & - & - & - & (17J & 02 \\
\hline PUE-7 & EUO-2 & & 0.085 & 25 & 16.00 & 216 & 7.40 & 7.40 & 5.70 & 150 & 91 \\
\hline $10 \mathrm{C}$ & 200 & & 0.000 & -70 & 56.90 & 10 & - & - & - & 100 & 91 \\
\hline PUE-8 & EUO-3 & IFDA & 0.156 & 25 & 27.60 & 212 & 13.00 & 9.10 & 7.70 & 152 & 96 \\
\hline $10 \mathrm{D}-0$ & J & 11010 & & -70 & 57.80 & 10 & - & - & - & 152 & 90 \\
\hline PUE-9 & EUO-4 & & 0.217 & 25 & 28.90 & 202 & 14.40 & 12.60 & 8.70 & 155 & 99 \\
\hline $10 \mathrm{~L}-3$ & $20 v^{-4}$ & & 0.217 & -70 & 62.40 & 11 & - & - & - & 100 & 97 \\
\hline PUE-10 & EUO-5 & & 0.271 & 25 & 24.00 & 172 & 22.30 & 11.30 & 8.30 & 156 & 100 \\
\hline & & & & -70 & 79.10 & 11 & - & - & - & & \\
\hline
\end{tabular}

The adhesion strength for EUO-DGU mixtures with metals using AEP as a hardener was the highest at the maximal DGU content, and the same results were obtained for the tensile strength of the cured material. The engineer strength of PUE- 5 with the volume fraction of the DGU $v_{2}=0.271$ was higher than that of PUE-1 (0.01) because it increased 9.1 MPa to $18.60 \mathrm{MPa}$. The pull-off bonding strength for the polymer-steel system increased by 1.95 times because it 


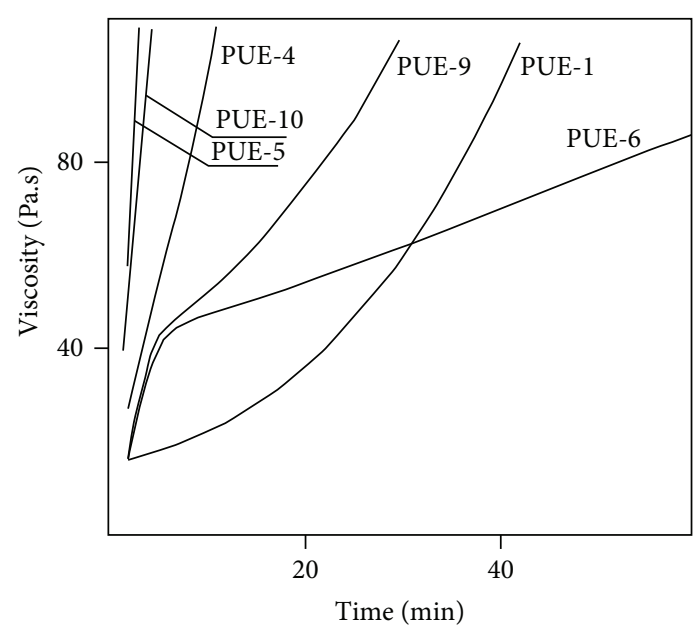

FIGURE 4: Dynamic viscosity vs. time dependences during curing PUE at $25^{\circ} \mathrm{C}$.

increased from 4.30 to $8.40 \mathrm{MPa}$. The shear bonding strength increased for the polymer-aluminium system by 2.34 times, from 3.2 to $7.50 \mathrm{MPa}$.

Similar results were obtained using IFDA as a hardener, but the maximum strength was realized at a molar fraction of DGU in the mixture of $v_{2}=0.217$. The tensile strength increased by 4 times, from $7.22 \mathrm{MPa}$ (PUE-6) to 28.90 MPa (PUE-9). The pull-off bonding strength for polymer-steel system increased by 2.8 times, from 4.50 to 12.60 MPa (from PUE-6 to PUE-9). The shear bonding strength for polymer-aluminium system increased by 2.4 times, from 3.6 to $8.7 \mathrm{MPa}$. It should be noted that all composites retained sufficient elasticity at $-70^{\circ} \mathrm{C}$. This is very important for the exploitation of materials in the extreme conditions of the Arctic.

Analysis of data obtained by the TMA method led to the conclusion that the softening temperature, $T_{S}$, naturally increases with an increase in the fraction of DGU in the mixture with EUO, irrespective of the curing agent type.

\section{Conclusions}

(1) The high-strength frost-resistant epoxy-urethane binder was developed. The glass transit temperature of this binder is lower than $-70^{\circ} \mathrm{C}$. It can be cured at room temperature within 24 hours using cycloaliphatic amines

(2) The influence of the peculiarities of the synthesis of epoxy-urethane oligomers based on oligotetramethyleneoxide diol with molecular weight $\approx 1400$ on their most important physical and physicomechanical properties was studied

(3) The creation of conditions that enable increasing the content of diglycidyl urethane fragments in the polymer chain in the synthesis of epoxy-urethane oligomers promoted a sharp increase in the strength and adhesion properties of the cured materials
(4) The presence of diglycidyl urethane fragments in the polymer chain of epoxy-urethane oligomers based on polyether did not significantly affect the glass transition temperature of the elastic phase of the cured polymeric materials. This finding, likely due to the microphase separation in the materials studied, makes the development of high-strength polymer matrices with a low glass transition temperature based on the studied oligomers a promising approach

\section{Data Availability}

The authors confirm that all the data used in this work have been provided in the text and that there are no restrictions or whatsoever to the use of the data in the text for scientific or commercial purposes. Any request could be directed to the corresponding author's email: senichev85@yandex.ru.

\section{Conflicts of Interest}

The authors declare that they have no conflicts of interest.

\section{Acknowledgments}

The study was financially supported by the Ministry of Education and Science of the Russian Federation, agreement no. 14.604.21.0192 (unique identifier RFMEFI60417X0192).

\section{References}

[1] D. S. Chen, C. C. M. Ma, H. C. Hsia, W. N. Wang, and S. R. Lin, "Preparation and characterization of cryogenic adhesives. I. Glycidyl-terminated polyurethane resins," Journal of Applied Polymer Science, vol. 51, no. 7, pp. 1199-1206, 1994.

[2] H. C. Hsia, C. C. M. Ma, M. S. Li, Y. S. Li, and D. S. Chen, "Glycidyl-terminated polyurethane modified epoxy resins: mechanical properties, adhesion properties, and morphology," Journal of Applied Polymer Science, vol. 52, no. 8, pp. 11371151, 1994.

[3] H. Yeganeh, S. Mehdipour-Ataei, and M. Ghaffari, "Preparation and properties of novel poly(urethane-imide)s via blending of reactive polyimide and epoxy-terminated urethane prepolymers," High Performance Polymers, vol. 20, no. 2, pp. 126-145, 2007.

[4] V. R. Mustafin, M. S. Shukurdzhiev, and F. Magrupov, "Modification of epoxy resins with furan-epoxyurethane oligomers," Plasticheskie Massy, vol. 19, p. 44, 1992.

[5] M. Pavlova, M. Draganova, and V. Kabaivanov, "Studies of the effect of a hardener on some properties of epoxyurethane adhesives with increase heat resistance," Polymer Communications, vol. 29, p. 80, 1988.

[6] L. F. Chuvilina, S. S. Simunova, G. V. Bryzgalina, O. A. Potsepnia, and I. I. Zaychenko, "Compound and a method for preparation thereof.," RU Patent 2291176.

[7] O. I. Sidorov, Y. M. Milekhin, A. A. Matveev, T. P. Poisova, K. A. Bykova, and N. V. Sadchikov, "A plasticizer-resistant strengthening composition based on polyester-urethane rubber with end epoxy-urethane groups," Polymer Science Series D, vol. 6, no. 2, pp. 125-133, 2013.

[8] A. D. Elchueva, M. M. Nazipov, A. A. Tabachkov, and A. G. Liakumovich, "Sealants based on oligodiene urethane 
epoxides," Russian Journal of Applied Chemistry, vol. 76, no. 3, pp. 487-490, 2003.

[9] A. V. Skripinets, Y. M. Danchenko, and A. V. Kabus, "A research on technological and physicochemical laws of manufacturing vibration-absorbing products based on epoxy-urethane polymer compositions," Eastern-European Journal of Enterprise Technologies, vol. 3, no. 11(75), p. 4, 2015.

[10] H. C. Hsia, C. C. M. Ma, and D. S. Chen, "Adhesion properties and phase separation behavior of glycidyl-terminated polyurethanes," Macromolecular Materials and Engineering, vol. 220, pp. 133-149, 1994.

[11] H. Yeganeh, H. Jamshidi, and S. Jamshidi, "Synthesis and properties of novel biodegradable poly( $\varepsilon$-caprolactone)/poly(ethylene glycol)-based polyurethane elastomers," Polymer International, vol. 56, no. 1, pp. 41-49, 2007.

[12] C. Y. Li, J. H. Chen, P. C. Chien, W. Y. Chiu, R. S. Chen, and T. M. Don, "Preparation of poly (IPDI-PTMO-siloxanes) and influence of siloxane structure on reactivity and mechanical properties," Polymer Engineering \& Science, vol. 47, no. 5, pp. 625-632, 2007.

[13] W. H. Chen, P. C. Chen, S. C. Wang, J. T. Yeh, C. Y. Huang, and K. N. Chen, "UV-curable PDMS-containing PU system for hydrophobic textile surface treatment," Journal of Polymer Research, vol. 16, no. 5, pp. 601-610, 2009.

[14] K. Madhavan and B. S. R. Reddy, "Synthesis and characterization of poly(dimethylsiloxane-urethane) elastomers: effect of hard segments of polyurethane on morphological and mechanical properties," Journal of Polymer Science Part A: Polymer Chemistry, vol. 44, no. 9, pp. 2980-2989, 2006.

[15] P. A. Edwards, G. Striemer, and D. C. Webster, "Novel polyurethane coating technology through glycidyl carbamate chemistry," Journal of Coatings Technology and Research, vol. 2, no. 7, pp. 517-527, 2005.

[16] M. S. Fedoseev, V. V. Tereshatov, and L. F. Derzhavinskaya, "Polymeric materials based on oligodieneurethane-epoxy oligomers," Russian Journal of Applied Chemistry, vol. 83, no. 8, pp. 1367-1371, 2010.

[17] M. A. Makarova, A. I. Slobodinyuk, V. V. Tereshatov, E. R. Volkova, and D. M. Kisel'kov, "Elastic and moisture-resistant compounds based on mixtures of oligotetraurethane diepoxide, epoxy-diane resin, and aromatic diamine," Polymer Science Series D, vol. 7, no. 3, pp. 166-169, 2014.

[18] V. N. Strel'nikov, V. Y. Senichev, A. I. Slobodinyuk et al., "Preparation and Properties of Frost-Resistant Room-Temperature-Curable Compounds Based on Oligoethertetraurethane Diepoxides of Various Chemical Structures," Russian Journal of Applied Chemistry, vol. 91, no. 3, pp. 463-468, 2018.

[19] H. Lee and K. Neville, Handbook of Epoxy Resins, McGrawHill, New York, NY, USA, 1967.

[20] A. I. Slobodinyuk, A. V. Pinchuk, Z. A. Vnutskikh, and V. V. Tereshatov, "Frost-Resistant Compositions on the Base of Oligourethane Diepoxide and Epoxydiane Resin with Improved Complex of Strength and Adhesive Properties," Klei Germetiki Tekhnologii, vol. 13, no. 8, p. 14, 2016.

[21] G. Socrates, Infrared and Raman Characteristic Group Frequencies: Tables and Charts, John Wiley \& Sons, New York, NY, USA, 2001.

[22] B. N. Tarasevich, FTIR-Spectra of Main Classes of Organic Compounds. Reference Materials, Moscow State University Publishing, Moscow, Russia, 2012.
[23] L. Guadagno, L. Vertuccio, A. Sorrentino et al., "Mechanical and barrier properties of epoxy resin filled with multi-walled carbon nanotubes," Carbon, vol. 47, no. 10, pp. 2419-2430, 2009.

[24] J. M. Piau and M. Piau, "Comment on "Origin of concentric cylinder viscometry" [J. Rheol. 49, 807-818 (2005)]. The relevance of the early days of viscosity, slip at the wall, and stability in concentric cylinder viscometry," Journal of Rheology, vol. 49, no. 6, pp. 1539-1550, 2005.

[25] M. Szycher, Szycher's Handbook of Polyurethanes, CRC Press, Boca Raton, FL, USA, Second edition, 2013.

[26] A. Mathew, S. Kurmvanshi, S. Mohanty, and S. K. Nayak, "Influence of diisocyanate, glycidol and polyol molar ratios on the mechanical and thermal properties of glycidylterminated biobased polyurethanes," Polymer International, vol. 66, no. 11, pp. 1546-1554, 2017.

[27] S. L. Huang and J. Y. Lai, "On the gas permeability of hydroxyl terminated polybutadiene based polyurethane membranes," Journal of Membrane Science, vol. 105, no. 1-2, pp. 137-145, 1995.

[28] V. V. Tereshatov, A. I. Slobodinyuk, V. N. Strel'nikov, I. L. Tutubalina, and M. A. Makarova, "Heterogeneous polymer materials based on oligodienetetraurethanediepoxide and oligoetherdiisocyanate," Polymer Science Series D, vol. 6, no. 1, pp. 5-8, 2013.

[29] J. W. Blake, W. P. Yang, R. D. Anderson, and C. W. Macosko, "Adiabatic reactive viscometry for polyurethane reaction injection molding," Polymer Engineering and Science, vol. 27, no. 16, pp. 1236-1242, 1987.

[30] C. Hepburn, Polyurethane Elastomers, Springer, Dordrecht, Netherlands, 1992.

[31] P. J. Flory, Principles of Polymer Chemistry, Cornell University Press, New York, NY, USA, 1953.

[32] E. R. Volkova, V. V. Tereshatov, and V. I. Karmanov, "Influence of the concentration of iron(III) tris(acetylacetonate) used as urethane formation catalyst on the structure and properties of cold-cure polyurethanes," Russian Journal of Applied Chemistry, vol. 84, no. 8, pp. 1414-1417, 2011.

[33] T. O. Ahn, S. U. Jung, H. M. Jeong, and S. W. Lee, "The properties of polyurethanes with mixed chain extenders and mixed soft segments," Journal of Applied Polymer Science, vol. 51, no. 1, pp. 43-49, 1994.

[34] V. V. Tereshatov, M. A. Makarova, V. Y. Senichev, E. R. Volkova, Z. A. Vnutskikh, and A. I. Slobodinyuk, "The role of the soft phase in the hardening effect and the rate dependence of the ultimate physico-mechanical properties of urethanecontaining segmented elastomers," Colloid and Polymer Science, vol. 293, no. 1, pp. 153-164, 2015. 


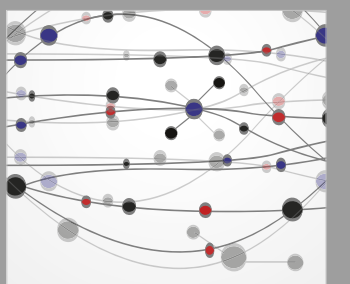

The Scientific World Journal
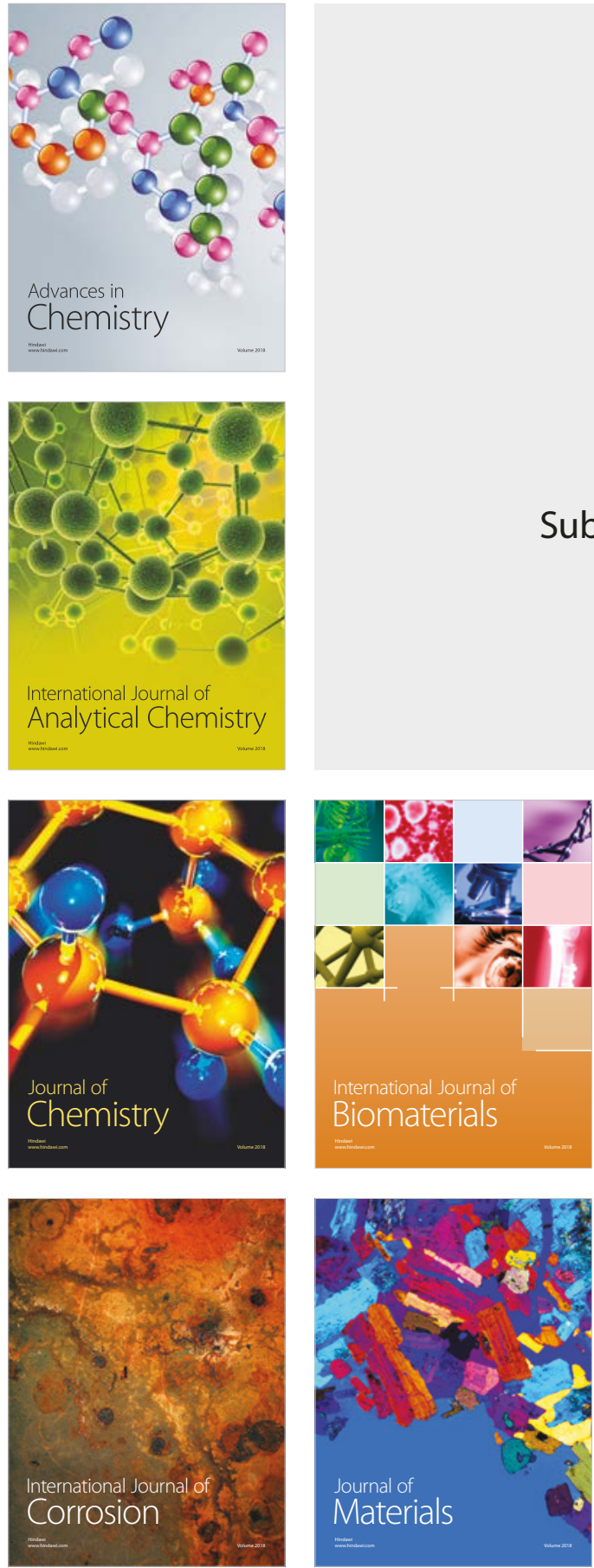

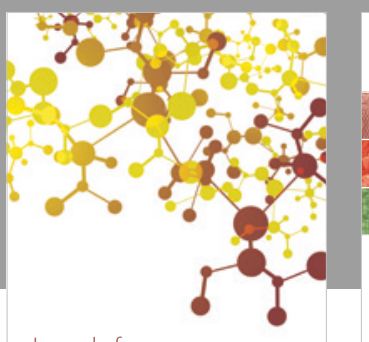

Journal of

Applied Chemistry
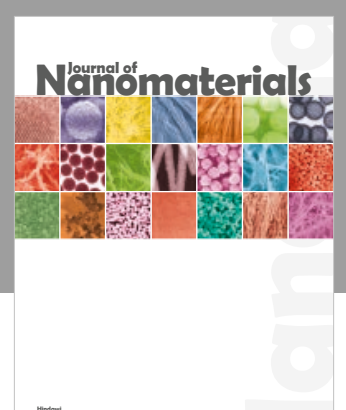

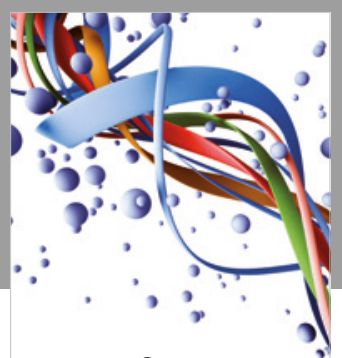

Scientifica

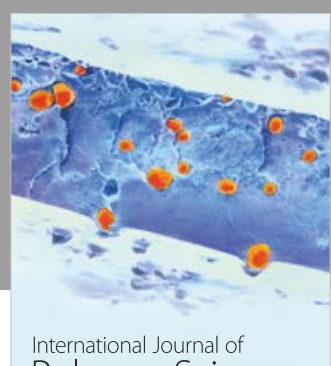

Polymer Science

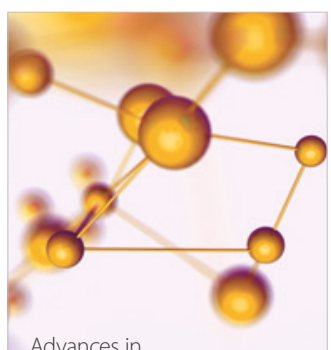

Physical Chemistry
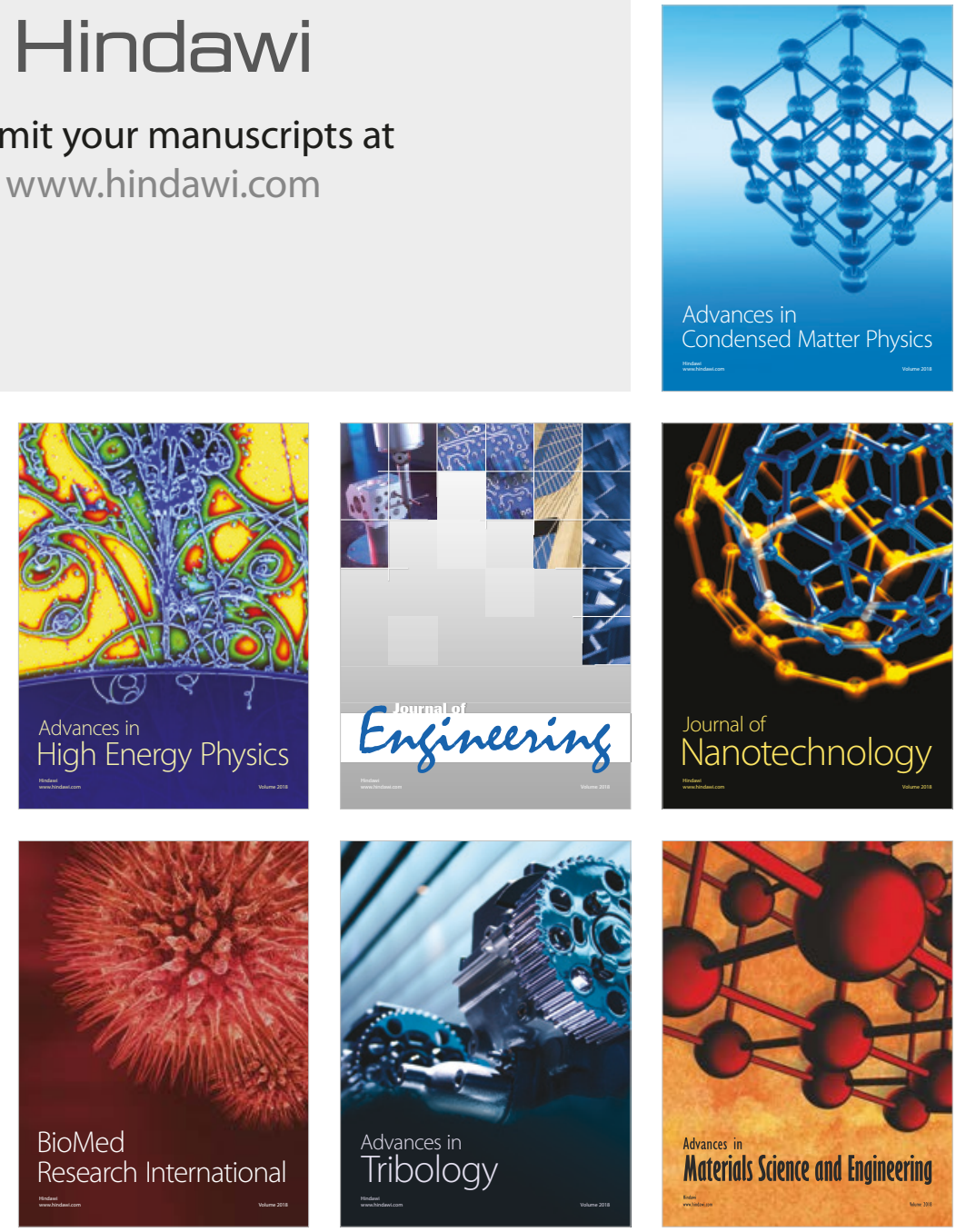